\title{
Saddleback syndrome in European sea bass Dicentrarchus labrax (Linnaeus, 1758): anatomy, ontogeny and correlation with lateral-line, anal and pelvic fin abnormalities
}

\author{
S Fragkoulis ${ }^{1}$, H Paliogiannis ${ }^{1}$, P Kokkinias ${ }^{1}, K_{\text {K }}$ Chiers $^{2}$, D Adriaens ${ }^{3}$ and \\ G Koumoundouros ${ }^{1}$ \\ 1 Biology Department, University of Crete, Heraklion, Crete, Greece \\ 2 Department of Pathology, Bacteriology and Poultry Diseases, Faculty of Veterinary Medicine, Ghent University, \\ Gent, Belgium \\ 3 Evolutionary Morphology of Vertebrates, Ghent University, Gent, Belgium
}

\begin{abstract}
This study focused on the anatomy and ontogeny of saddleback syndrome (SBS) in reared European sea bass. The abnormality was detected at an unusually high frequency (12-94\%) during a routine quality control in a commercial hatchery. Anatomically the abnormality was mainly characterized by the loss of $1-5$ hard spines and severe abnormalities of the proximal pterygiophores (anterior dorsal fin), size reduction of a few lepidotrichia, missing lepidotrichia and/or lepidotrichia of poor ossification (posterior dorsal fin). SBS was significantly correlated with abnormalities of the anal and pelvic fins in all the examined populations. Moreover, in juvenile fish, SBS was significantly correlated with an abnormal lack of sectors of the lateral line. The examination of early larval samples revealed that SBS was ontogenetically associated with severe abnormalities of the primordial marginal finfold, which developed at the flexion stage (ca $8.5-11.0 \mathrm{~mm}$ SL). Histologically, these abnormalities were associated with extensive epidermal erosion. The results are discussed in respect of the critical ontogenetic period and the possible causative factors of SBS in European sea bass. It is suggested that causative factors
\end{abstract}

Correspondence G Koumoundouros, Biology Department, University of Crete, Vassilika Vouton, 70013 Heraklion, Crete, Greece (e-mail: gkoumound@biology.uoc.gr) acted during a wide ontogenetic period including flexion and metamorphosis phases.

Keywords: dorsal fin, epidermal abnormalities, fish, skeletal abnormalities.

\section{Introduction}

The development of morpho-anatomical abnormalities in fish was first documented in the 16th century (Gudger 1936). Nowadays, morphoanatomical abnormalities are a frequent problem for product quality in finfish aquaculture. The minimum annual economic impact of abnormalities for European aquaculture has been estimated to be more than 50 million $€$ per year (reviewed by Boglione et al. 2013). They affect the skeleton, squamation, body pigmentation and body shape at mean frequencies ranging between seven and twenty per cent, and occasionally reaching up to 100\% (Mediterranean hatcheries, Koumoundouros 2010). Their development has been reported in almost all species under rearing conditions, especially during the larval and early juvenile phases (e.g. Koumoundouros et al. 1997; Mazurais et al. 2009; Izquierdo, Socorro \& Roo 2010; Koumoundouros 2010; Boglino et al. 2012; Boglione et al. 2013; Cobcroft \& Battaglene 2013). A wide range of factors, such as water temperature (e.g. Georgakopoulou et al. 2010), tank colour 
Table 1 Age, size (mean \pm SD) and number of fish per examination method for each sea bass sample

\begin{tabular}{|c|c|c|c|c|c|c|}
\hline Code & Stage & Age (dph) & $\mathrm{SL}(\mathrm{mm})$ & X-rays & A-A stain & EGMA/Histology \\
\hline Juv & Juveniles & 150 & $82.2 \pm 4.2$ & 100 & & \\
\hline P1 & Metamorphosis & 38 & $14.8 \pm 0.8$ & & 49 & \\
\hline P2 & Metamorphosis & 38 & $14.3 \pm 1.1$ & & $50-53$ & \\
\hline P3 & Metamorphosis & 38 & $13.1 \pm 0.6$ & & 50 & \\
\hline P4 & Metamorphosis & 38 & $13.6 \pm 1.0$ & & 50 & \\
\hline P5 & Metamorphosis & 38 & $14.5 \pm 1.2$ & & 49 & \\
\hline P6 & Metamorphosis & 38 & $14.5 \pm 0.9$ & & $40-50$ & \\
\hline \multirow[t]{3}{*}{ P7 } & First feeding & 5 & $4.1 \pm 0.3$ & & 50 & 50 \\
\hline & Flexion & 25 & $9.1 \pm 0.7$ & & 50 & $50 / 4$ \\
\hline & Metamorphosis & 45 & $17.0 \pm 1.0$ & & 50 & \\
\hline \multirow[t]{3}{*}{ P8 } & First feeding & 8 & $4.5 \pm 0.2$ & & 50 & 50 \\
\hline & Flexion & 20 & $8.3 \pm 0.5$ & & 50 & $50 / 3$ \\
\hline & Metamorphosis & 49 & $18.6 \pm 1.0$ & & 50 & \\
\hline
\end{tabular}

EGMA, stereoscopic examination of gross morphological abnormalities of the marginal finfold; dph, days post-hatching; SL, standard length; A-A, alizarin red $S$ and Alcian blue double staining.

In first-feeding samples, notochord length was measured.

(Cobcroft \& Battaglene 2009) and nutrition during the larval period (e.g. Takeuchi et al. 1998; Mazurais et al. 2009), velocity of water currents during metamorphosis and early juvenile phase (Divanach et al. 1997; Sfakianakis et al. 2006), and genetic background (e.g. Bardon et al. 2009; Sawayama, Asahina \& Takagi 2014; Negrín-Báez et al. 2015), have been shown to cause the development of abnormalities.

Despite the increasing number of studies on the development of morpho-anatomical abnormalities, the latter continue affecting reared fish populations, occasionally with new types arising (e.g. Loizides et al. 2014). This fact is mainly attributed to the large number of potential critical factors, the lack of knowledge concerning the species-specific preferences for optimal development, and the high sensitivity of the rearing process to human mistakes (reviewed by Boglione et al. 2013). As an element of solution, early and precise diagnosis of abnormalities will assist in quality monitoring programmes undertaken by the hatcheries. The thorough study of the ontogeny and anatomy of abnormalities will serve to this goal,
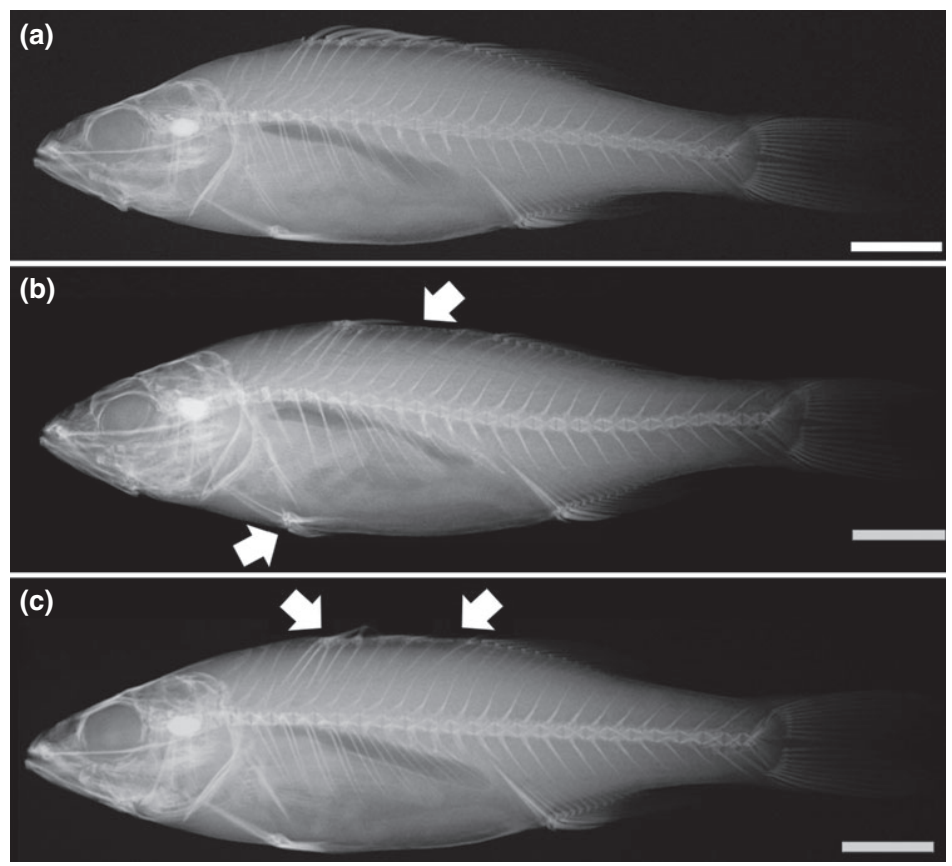

Figure 1 Deformities of the dorsal and pelvic fins in sea bass juveniles. (a) normal. (b-c), juveniles with lack of dorsal fin spines (arrows) and with unilaterally missing pelvic fin (b juvenile, ventral arrow). Scale bars equal to $10 \mathrm{~mm}$. 


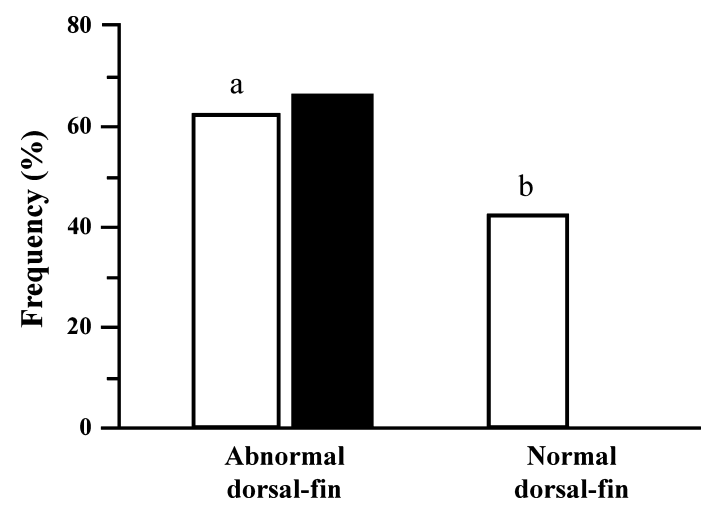

Figure 2 Frequency of the lateral-line abnormalities (missing sectors, open bars) and of the pelvic fin deformities (filled bars) in the juveniles with normal and abnormal dorsal fin. Different letters above the bars indicate statistically significant differences $(P<0.05)$.

and additionally will support the effective hypothesis testing for the identification of crucial causative factors (Koumoundouros 2010). Finally, the anatomical study will allow the objective categorization of deformed fish, according to the severity of the deformity.

The term saddleback syndrome (SBS) was first introduced by Tave, Bartels \& Smitherman (1983) to describe the partial-to-complete lack of dorsal fin in tilapia Sarotherodon aureus. Following the descriptions of Tave et al. (1983), SBS was associated with severe abnormalities of the dorsal fin pterygiophores and by severe depression of the dorsal profile of the body. Since then, SBS has been reported to develop in a variety of fish species under rearing conditions (Dentex dentex Koumoundouros, Divanach \& Kentouri 2001; Pagellus erythrinus - Boglione Costa, Di Dato, Ferzini, Scardi \& Cataudella 2003; Epinephelus akaara - Setiadi Tsumura, Kassam \& Yamaoka 2006; Sparus aurata - Koumoundouros 2010; Lates calcarifer - Cobcroft \& Battaglene 2013). Moreover, SBS has been reported in wild fish around the world (ten species in Biscayne Bay, Florida - Browder et al. 1993; Sparisoma cretense, Aegean Sea - Koumoundouros 2008; Acanthopagrus australis, South East Queensland - Diggles 2013). Interestingly, Diggles (2013) reported an almost sixfold increase of the incidence of SBS in wild $A$. australis during a period of 20 years. To our knowledge, little is known about the causative factors of SBS. In D. labrax SBS deformities were induced by unfavourable dietary levels of vitamin A (Mazurais et al. 2009), whereas in S. aureus SBS was attributed to the action of an autosomal dominant gene (Tave et al. 1983).

European sea bass (Dicentrarchus labrax) is a major species for European aquaculture, with an annual production of 128 thousand tons of market-size fish and 484 million juveniles in 2013 (FEAP 2014). Although published data about the rate of deformities are scarce for commercial hatcheries, SBS is considered as an abnormality of rather negligible incidence in reared sea bass. In the present study, (i) we document the
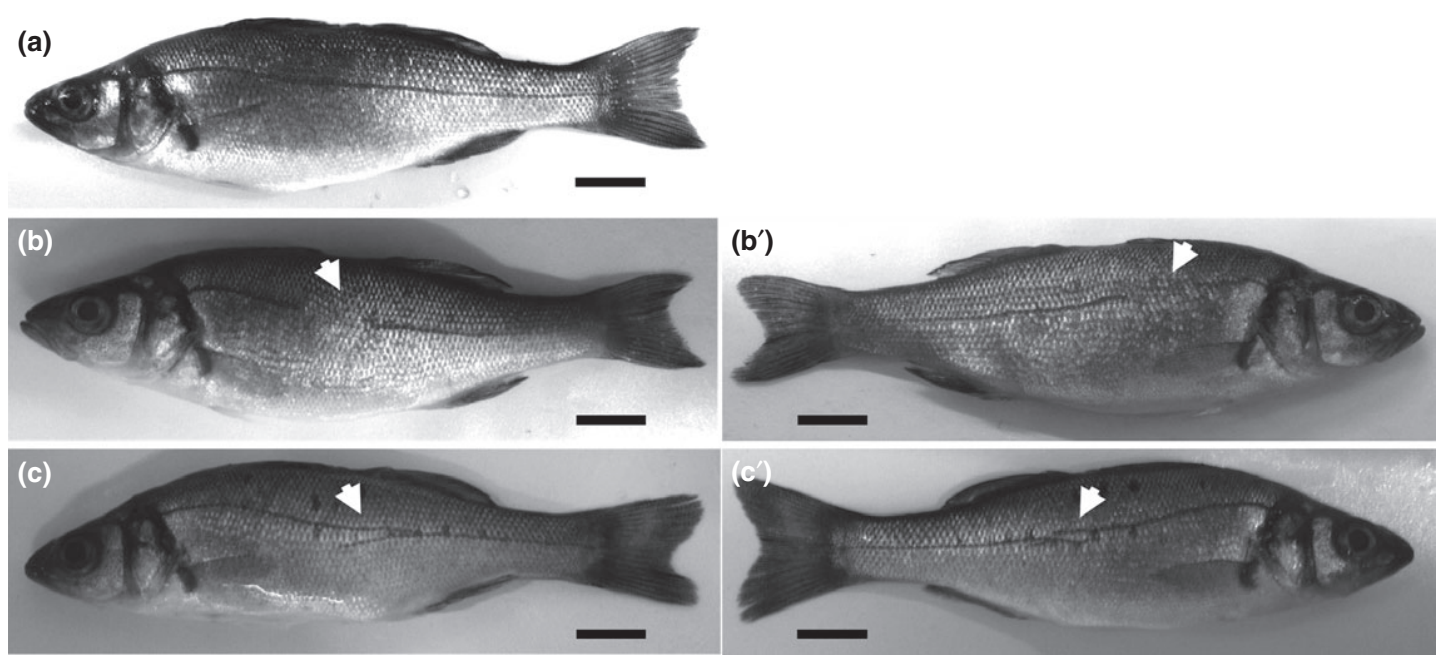

Figure 3 Abnormalities of the lateral line in sea bass juveniles. (a) normal fish. (b-b') bilaterally missing sector of the lateral line. $\left(\mathrm{c}-\mathrm{c}^{\prime}\right)$ bilaterally double (overlapping) lateral line. Scale bars equal to $10 \mathrm{~mm}$. 

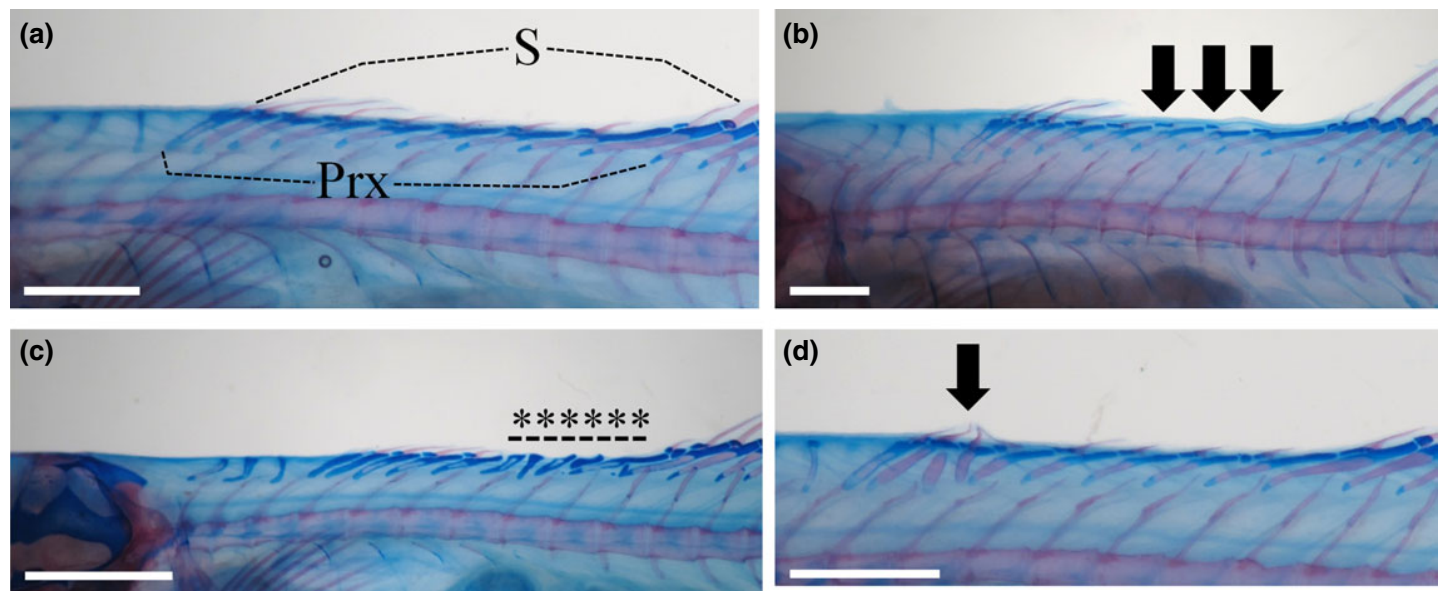

Figure 4 Representative cases of saddleback syndrome affecting the anterior dorsal fin in the larval samples. (a) normal (14.5 mm $\mathrm{SL})$. (b), missing hard spines (arrows) (14.5 mm SL). (c) missing hard spines (asterisks), associated with deformed pterygiophores (13.0 mm SL). (d) convergent hard spines (arrow), associated with pterygiophore malformations (15.5 mm SL). Prx, proximal pterygiophore; $S$, hard spine. Scale bars equal to $1 \mathrm{~mm}$.

development of SBS in D. labrax populations of a commercial hatchery, at an unusually high frequency (12-94\%), and (ii) we study the anatomy of the abnormality and its ontogenetic correlations with other morpho-anatomical abnormalities.

\section{Materials and methods}

Samples were taken from a population of sea bass juveniles [145-150 days post-hatch (dph), 70$90 \mathrm{~mm}$ standard length (SL)], during a routine quality control in a commercial hatchery. Juveniles were anaesthetized (ethyleneglycol-monophenylether, Merck, $0.2-0.5 \mathrm{~mL} \mathrm{~L}^{-1}$ ) and examined for the presence of SBS. Subsequently, a random sample of 50 normal and 50 abnormal individuals was taken. In each individual, both sides of the body were photographed to examine the presence of lateral-line abnormalities (Carrillo et al. 2001; Sfakianakis et al. 2013). Sampled juveniles were then $\mathrm{X}$-rayed and examined for the presence of skeletal abnormalities (Koumoundouros et al. 2000).

The development of SBS was furthermore examined in random samples of 40-100 individuals which were taken from eight larval populations of sea bass. All populations were reared at the same hatchery simultaneously till the sampling of juveniles. From six populations, samples were taken at the end of larval rearing phase (P1-P6; Table 1). The other two larval populations (P7P8) were sampled at first feeding, flexion stage and at metamorphosis (Table 1). Larval samples were anaesthetized (ethyleneglycol-monophenylether, Merck, $0.2-0.5 \mathrm{~mL} \mathrm{~L}^{-1}$ ), fixed in $5 \%$ phosphate-buffered formalin and stained for bone and cartilage (Walker \& Kimmel 2007). Each specimen was photographed individually, for the examination of skeletal abnormalities. The standard length (distance between the tip of snout and the base of the middle caudal ray) was measured by means of tpsDig2 software (Rohlf 2010). For the comparative understanding of the abnormality ontogeny, fin anatomy was illustrated on an ontogenetic series of five indicative normal specimens. The description of abnormalities followed the terminology of Koumoundouros (2010). The terminology of osteological development followed Harder (1975) and Matsuoka (1987).

Of the P7-P8 early larval samples, only half of the samples were stained for bone and cartilage, whereas the remaining individuals were kept in the fixative solution for further microscopical analysis of gross morphological abnormalities and histology (Table 1). Specimens were examined for the presence of abnormalities of the primordial marginal finfold, a prodrome of SBS in other fish species (Koumoundouros et al. 2001).

A total of seven specimens were selected for histological screening of the skin tissue phenotype. Two specimens were embedded in paraffin (Histosec 'Merck' melting point $56-58{ }^{\circ} \mathrm{C}$ ), and $5-\mu \mathrm{m}$ sections (using a Microm HM 360 microtome with SEC 35 low-profile blades) were 

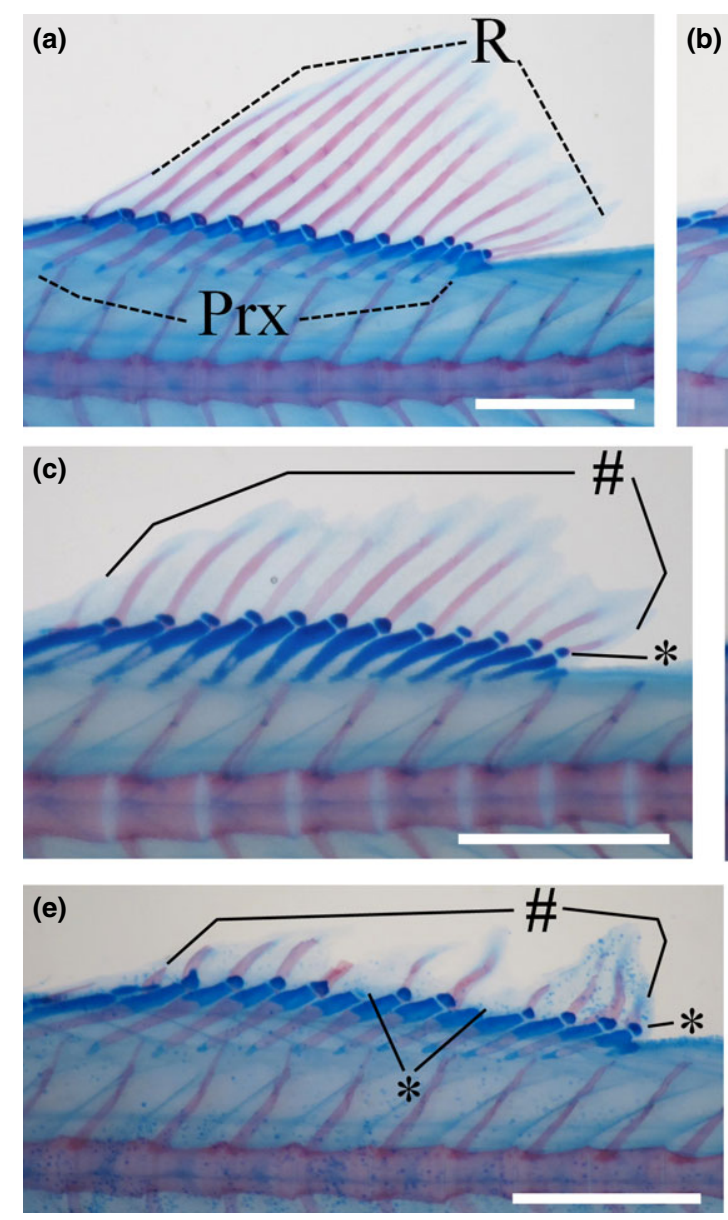
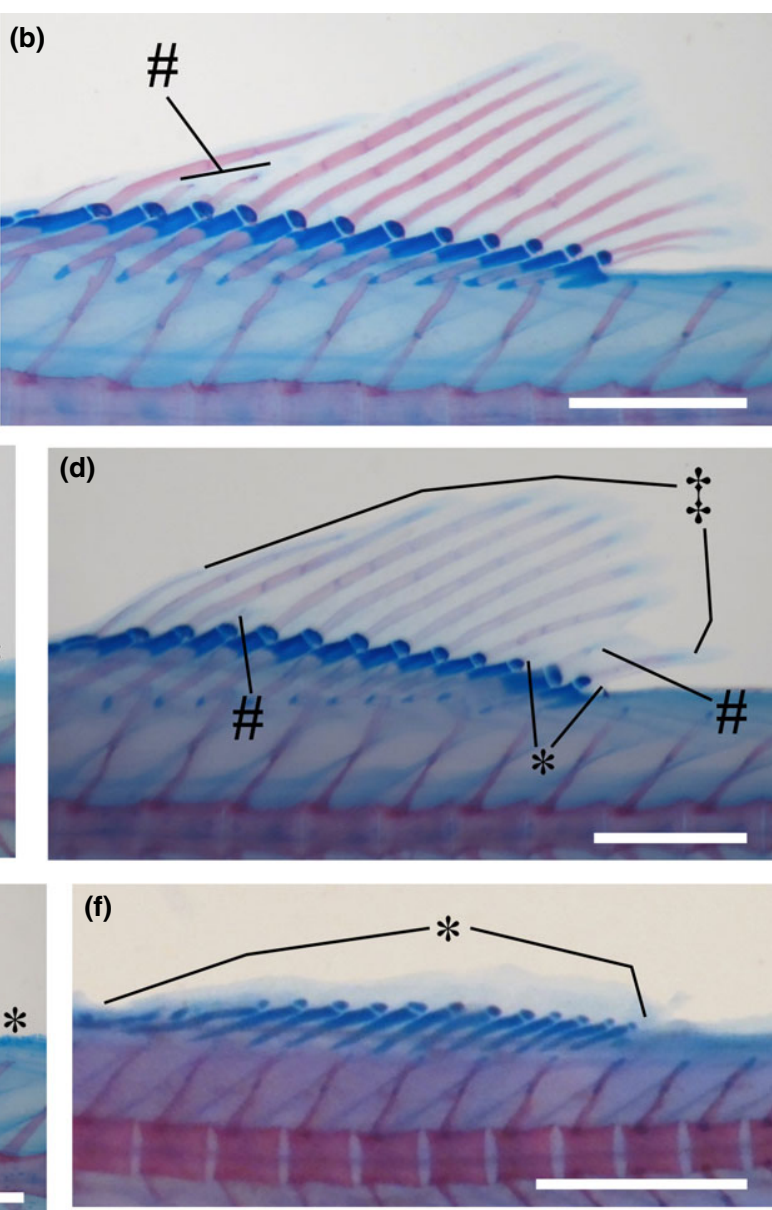

Figure 5 Representative cases of saddleback syndrome affecting the posterior dorsal fin in the larval samples. (a) normal (15.6 mm $\mathrm{SL})$. (b) size reduction of two lepidotrichia (\#) $(13.0 \mathrm{~mm} \mathrm{SL}$ ). (c) size reduction of all the lepidotrichia (\#), associated with missing lepidotrichium of the last pterygiophore $(*)(12.7 \mathrm{~mm} \mathrm{SL})$. (d) poor ossification ( $)$, size reduction (\#) and complete lack of lepidotrichia $\left(^{*}\right)(15.0 \mathrm{~mm} \mathrm{SL})$. (e) size reduction (\#) or complete lack $\left(^{*}\right)$ of lepidotrichia $(14.5 \mathrm{~mm} \mathrm{SL})$. F, complete lack of all the lepidotrichia $\left.{ }^{*}\right)(12.5 \mathrm{~mm} \mathrm{SL}$ ). Prx, proximal pterygiophore; R, lepidotrichium. Scale bars equal to $1 \mathrm{~mm}$.

stained using different protocols: haematoxylin and eosin, Masson trichrome staining and toluidine. One specimen was embedded in Epon and sectioned using a Microm HM 360 microtome with diamond knife $8 \mathrm{~mm}$ 'diatome', with $2-\mu \mathrm{m}$ sections stained in toluidine. Screening of embedding and staining methods showed that Epon sections with toluidine staining provided most detail and kept the physical integrity of the tissue intact. As such, the remaining four specimens (two normal and two abnormal specimens) were sectioned as such. For the analysis, 50 sections (10 sections at five positions within a region) were obtained from five regions in the body: caudal fin region, distal caudal peduncle region, proximal caudal peduncle region, hindgut region and midgut region. Sections were covered with a cover slide, using DPX, and imaged using a Reichert-Jung Polyvar light microscope (Reichert Depew), equipped with a Colorview 8 digital camera (Olympus). Terminology of pathological phenotypes of the skin followed Kumar, Abbas \& Aster (2015).

The examined fish populations were established from eggs that were obtained from the spontaneous spawning of one broodstock population ( 40 breeders, 1:1 sex ratio). Egg incubation and larval rearing were performed according to the standard methodology for the intensive rearing of European sea bass. Egg incubation and larval phases were performed in indoor tanks of $4.5 \mathrm{~m}^{3}$ at an initial stocking density of $50 \mathrm{eggs} \mathrm{L}^{-1}$. Larvae were 


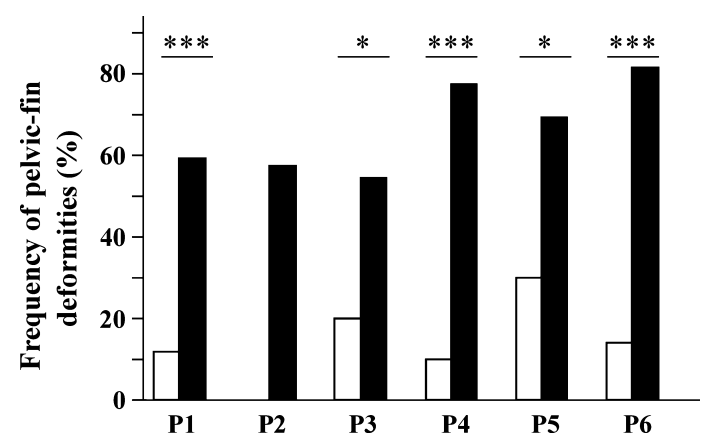

Figure 6 Frequency of pelvic fin deformities in larvae with normal (open bars) or deformed (filled bars) dorsal fin in six different fish populations (P1-P6). Asterisks indicate statistically significant differences at $P<0.05(*)$ or $P<0.001(* * *)$.

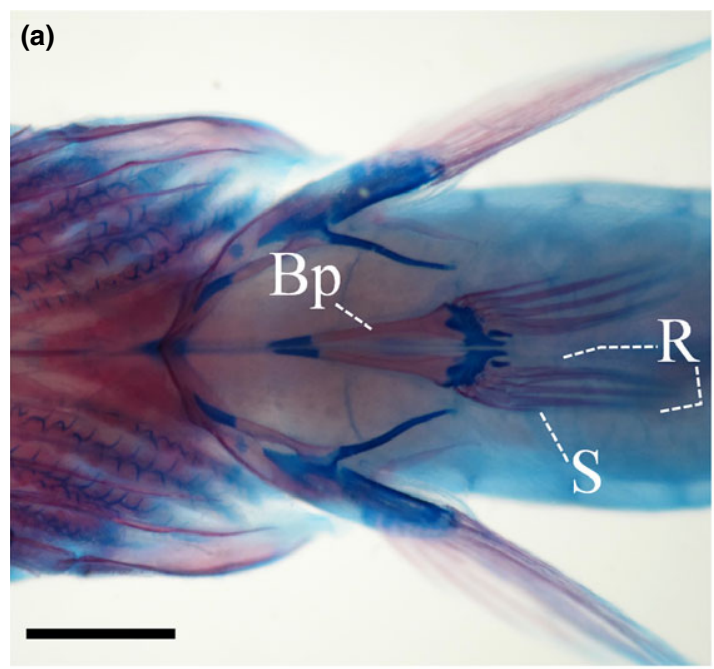

(c)

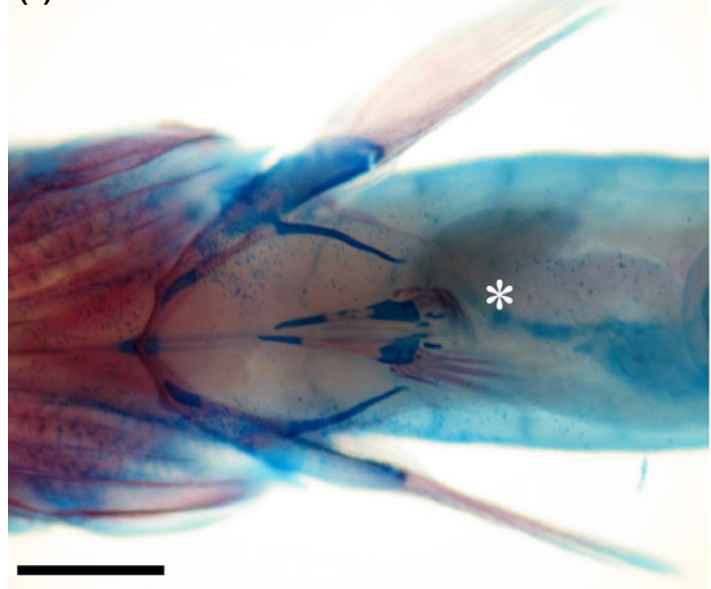

reared in the presence of background phytoplankton (Chlorella sp.), with feeding on enriched rotifers (8-28 dph, Red Pepper; Bern Aqua), gradual provision of enriched Artemia nauplii (14$46 \mathrm{dph}$, Easy DHA Selco; INVE), and finally on inert commercial diet $(>35 \mathrm{dph}$, Caviar; Bern Aqua). Water temperature was $15.5^{\circ} \mathrm{C}$ during the embryonic and yolk-sac larval stages, whereas it was raised to $18.5^{\circ} \mathrm{C}$ during the feeding larval stage $\left(0.5^{\circ} \mathrm{C} \mathrm{day}^{-1}\right)$. Tanks were supplied with borehole water of $35 \mathrm{~g} \mathrm{~L}^{-1}$ salinity and $7.8 \mathrm{pH}$. Oxygen saturation was $90-95 \%$ and water exchange rate was $50-400 \%$ of the tank volume day $^{-1}$.

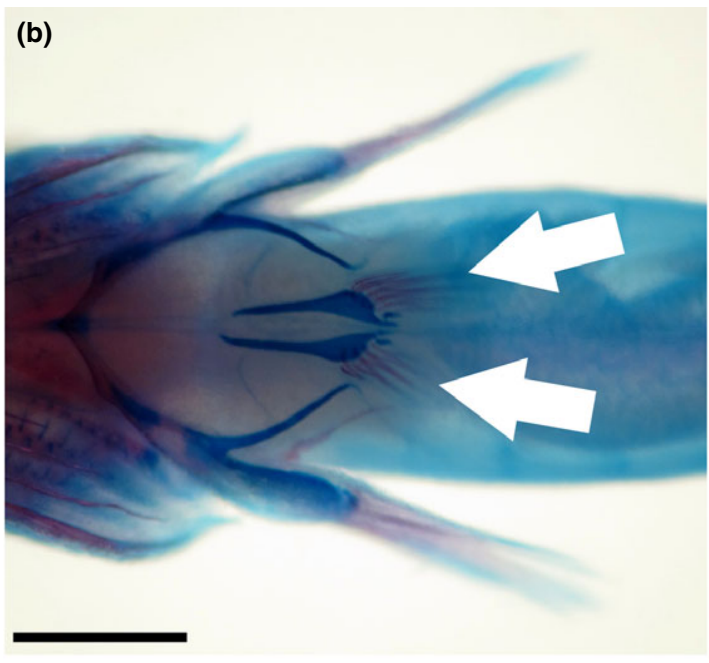

(d)

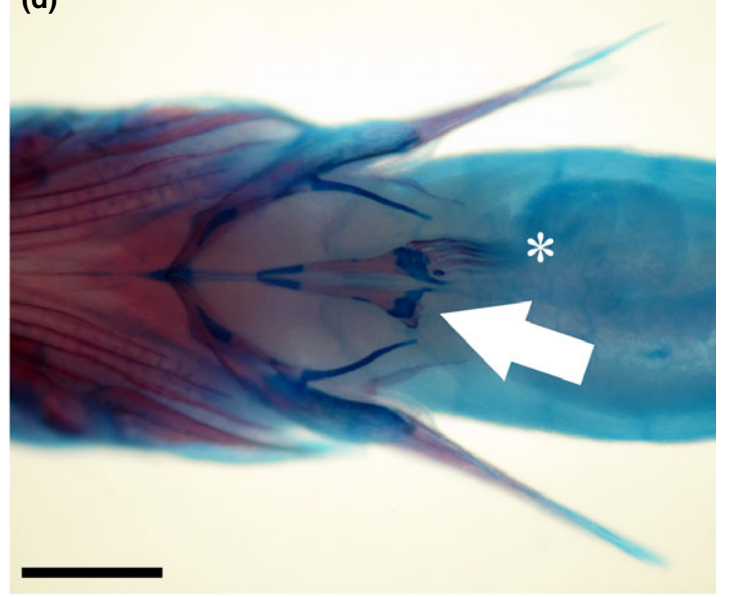

Figure 7 Representative cases of pelvic fin deformities in the larval samples. (a) normal (15.5 mm SL). (b) size reduction of the hard spine and lepidotrichia (arrows), associated with asymmetric basipterygia (14.0 mm SL). (c) twisted hard spine and lepidotrichia $(*)$ and asymmetric basipterygia $(15.0 \mathrm{~mm} \mathrm{SL}$ ). (d) missing (arrow) and twisted $(*)$ hard spine and lepidotrichia (15.0 mm SL). Bp, basipterygium; S, hard spine; R, lepidotrichium. Scale bars equal to $1 \mathrm{~mm}$. 

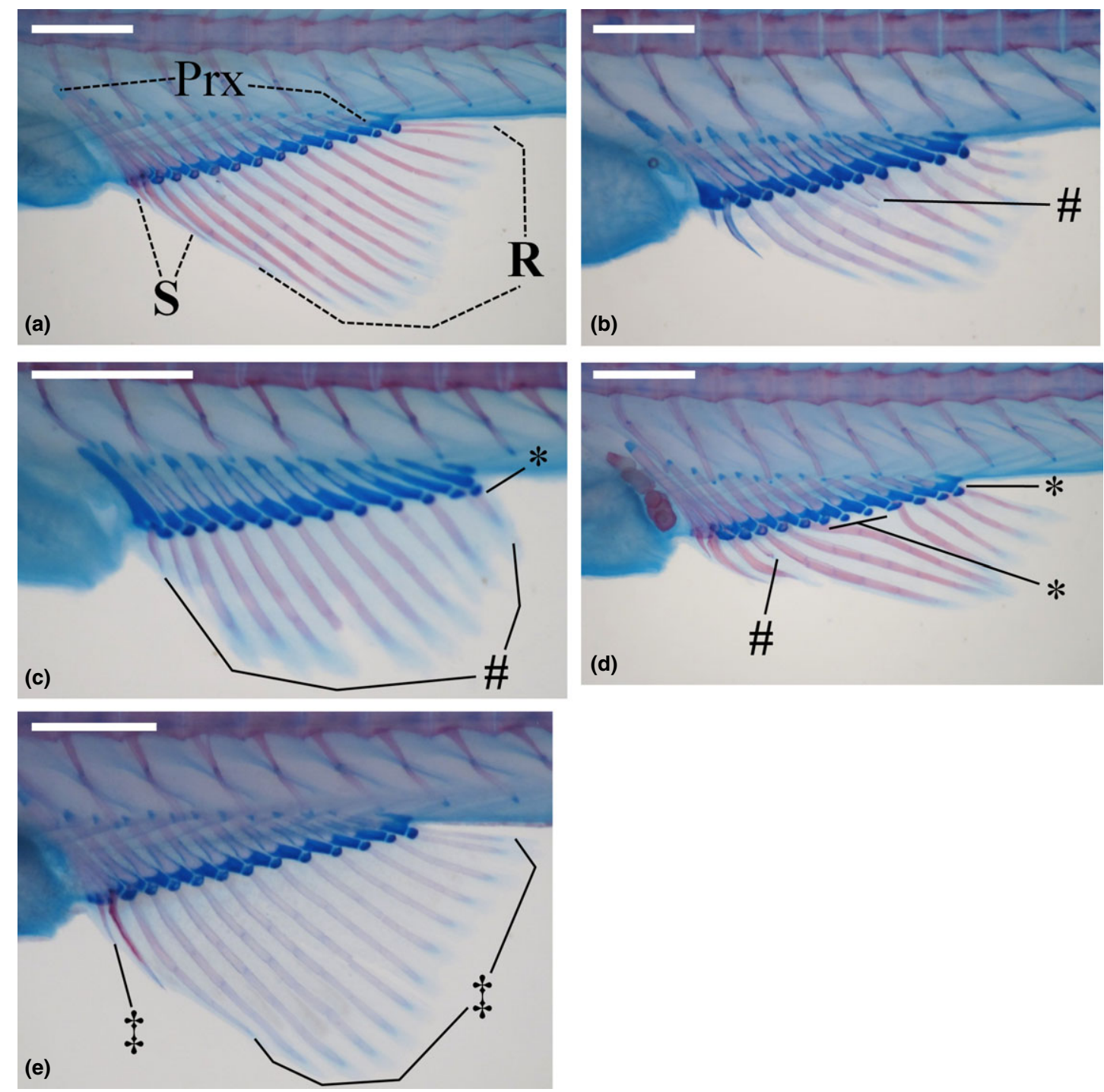

Figure 8 Representative cases of abnormalities affecting the anal fin in the larval samples. (a) normal (15.5 mm SL). (b) size reduction of two lepidotrichia (\#) (14.0 mm SL). (c) size reduction of all the lepidotrichia (\#), associated with missing lepidotrichium of the last pterygiophore $\left(^{*}\right)(11.5 \mathrm{~mm} \mathrm{SL})$. (d) size reduction (\#) or complete lack $\left(^{*}\right)$ of lepidotrichia $(15.0 \mathrm{~mm} \mathrm{SL})$. (e) poor ossification (‡) of lepidotrichia (15.0 mm SL). Prx, proximal pterygiophore; S, hard spine; R, lepidotrichium. Scale bars equal to $1 \mathrm{~mm}$.

The significance of the differences in the frequency of abnormalities among groups was tested by a $G$-test (Sokal \& Rohlf 1981).

\section{Results}

\section{Juvenile samples}

Saddleback syndrome was present in $12 \%$ of the examined juvenile population. The abnormality was characterized by the loss of hard spines of the pterygiophores 3-7 (92\% of the cases) and rarely of the anterior two pterygiophores $(8 \%$ of the cases) (Fig. 1). The abnormality was highly associated with a partial or total lack of pelvic fin rays (in 66\% of the fish with SBS vs. $0 \%$ of the fish without SBS; Figs $1 \&$ 2). All juveniles presented severe abnormalities of the lateral line, mainly in the form of bilaterally or unilaterally missing sectors $\left(42-62 \%\right.$; Fig. 3b- $\left.\mathrm{b}^{\prime}\right)$ and rarely in the form of unilaterally or bilaterally double (overlapping) lateral line (12-22\%; Fig. 3c- $\left.\mathrm{c}^{\prime}\right)$. The $G$-test 


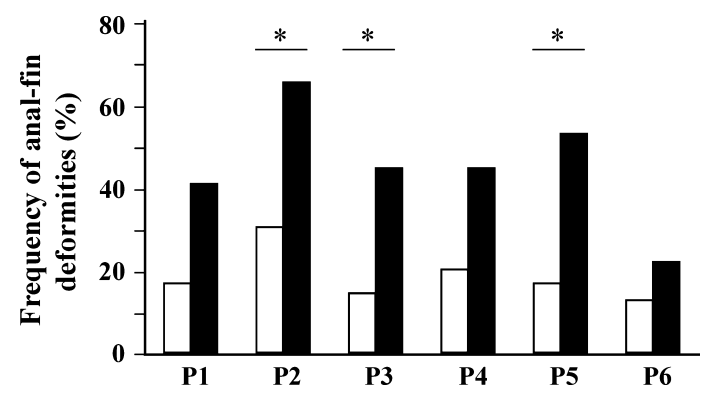

Figure 9 Frequency of anal fin deformities in larvae with normal (open bars) or deformed (filled bars) lepidotrichia of the posterior dorsal fin in six different fish populations (P1-P6). Asterisks indicate statistically significant differences $(P<0.05)$.

revealed that the presence of missing sectors on the lateral line was significantly more frequent in the SBS than in the non-SBS fish $(62 \%$ vs. $42 \%$, $P<0.05$; Fig. 2). No significant differences were found in the frequency of double lateral line between SBS and non-SBS juveniles (12\% vs. 22\%, $P>0.05)$.
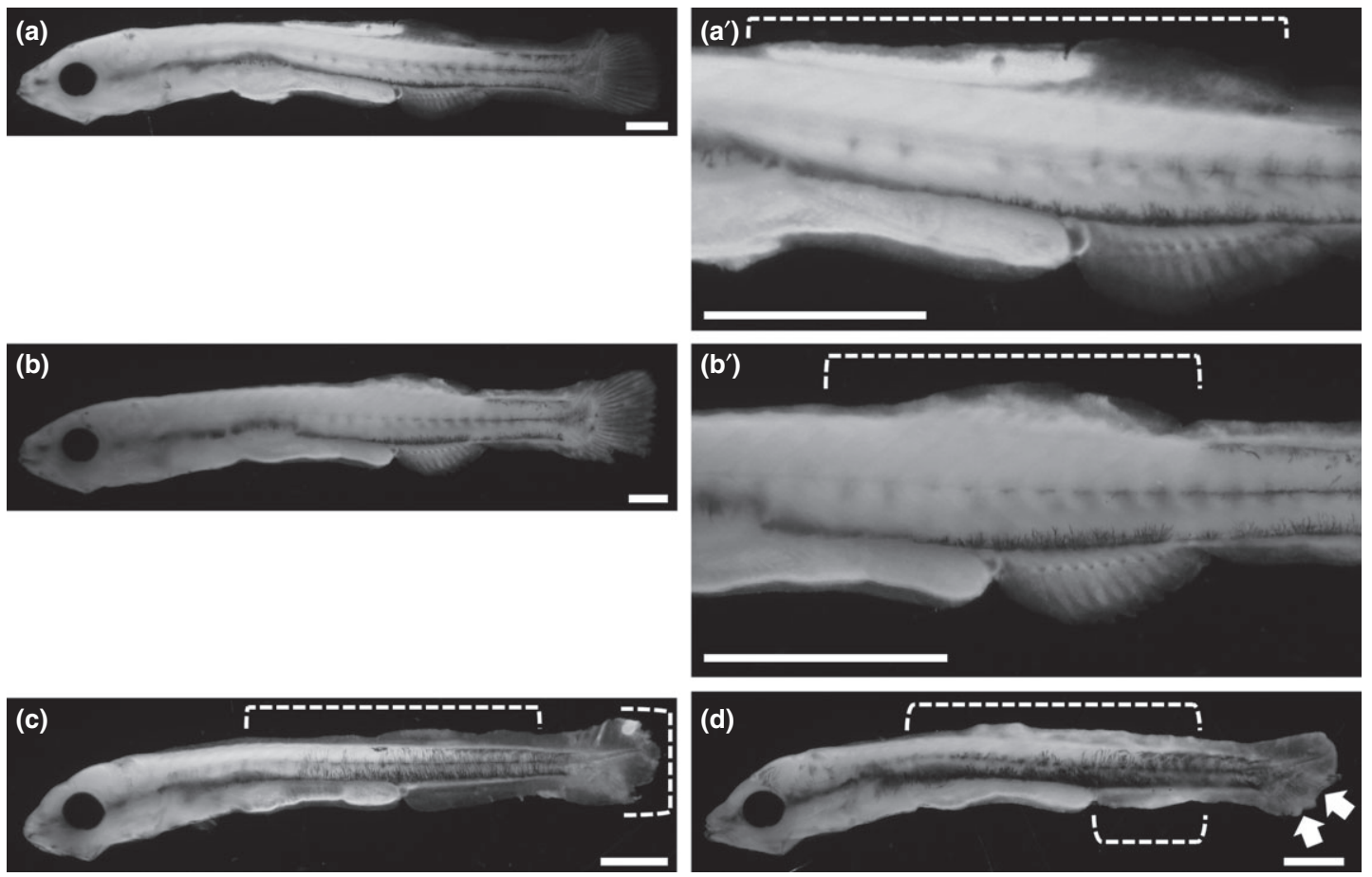

Figure 10 Representative cases of abnormalities of the primordial marginal finfold (Pmf) in the larval samples. (a-a') opaque, necrotic-like Pmf in the dorsal area (dashed line) $(9.6 \mathrm{~mm} \mathrm{SL}) .\left(\mathrm{b}-\mathrm{b}^{\prime}\right)$ opaqueness and size reduction of Pmf (dashed line) (10.8 mm SL). (c) severe abnormalities of the Pmf at the dorsal and caudal areas (dashed lines) (8.5 mm SL). (d) severe abnormalities, opaqueness and size reduction of the Pmf at the dorsal, anal (dashed lines) and caudal area (arrows) (9.4 mm SL). Scale bars equal to $1 \mathrm{~mm}$. 
(a)
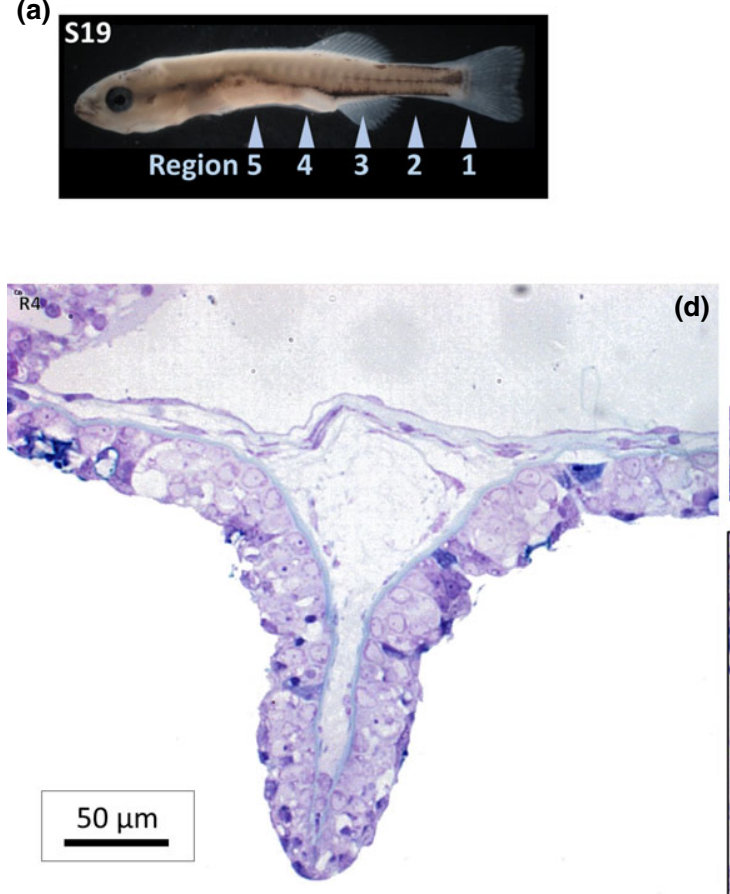

d)
R4

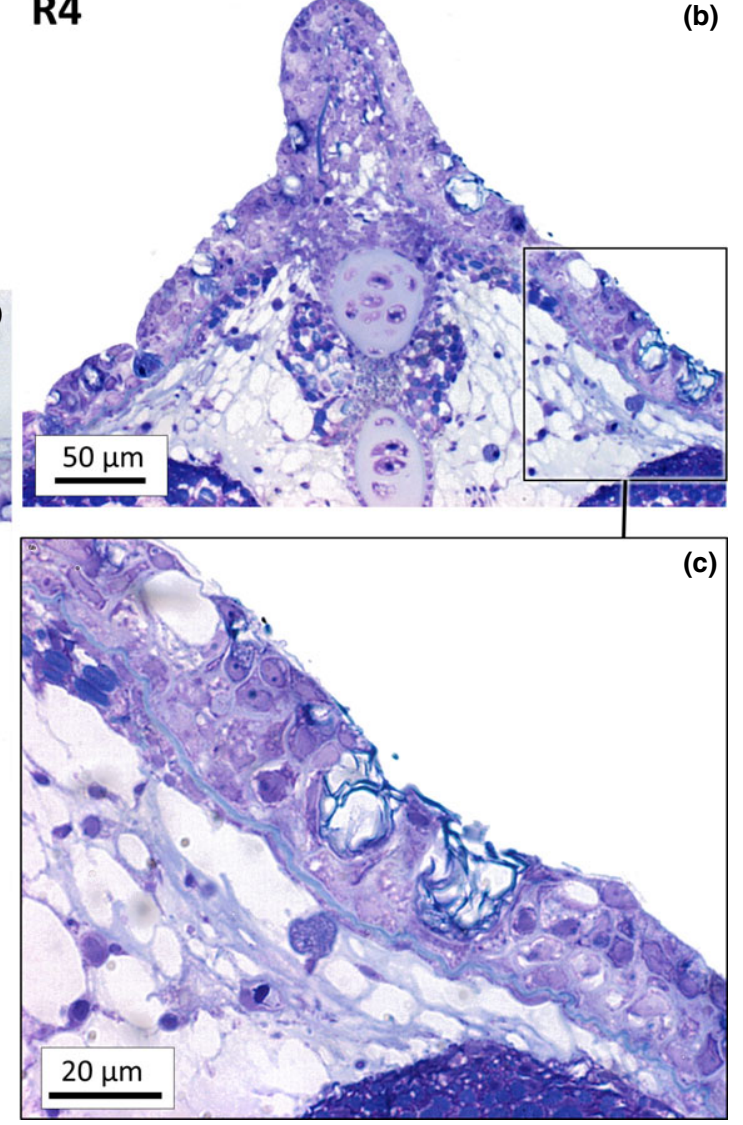

Figure 11 Skin histology in a normal specimen (specimen S19): (a) habitus of the specimen, showing the different regions from which sections were obtained. (b) overview of the dorsal fin fold in region 4. (c) inset of fig B, showing a detail of the epithelial cells and gobletlike cells (Epon sections, stained with toluidine). (d) detail of the ventral fin fold.

the non-SBS fish $(P<0.05$; Fig. 6). Pelvic fin abnormalities were evident in the form of size reduction of the rays and/or asymmetric development of the basipterygia (Fig. 7b-d), twists of rays (Fig. $7 \mathrm{c}-\mathrm{d}$ ) or missing rays (Fig. $7 \mathrm{~d}$ ). Similar to the abnormalities of the posterior dorsal fin, anal fin abnormalities consisted of size reduction of a few lepidotrichia (Fig. 8b-d), missing lepidotrichia (Fig. 8c-d) and/or lepidotrichia of poor ossification (Fig. 8e). Anal fin abnormalities were significantly associated with the abnormalities of the posterior dorsal fin. In three of the six examined populations, SBS fish presented significantly higher incidence of anal fin abnormalities than the non-SBS fish (Fig. 9).

The examination of the samples taken at first feeding (P7-P8 populations; Table 1) showed that Pmf abnormalities were negligible and in the form of light shape alterations (2-4\%). At the flexion stage, $\quad 30-34 \%$ of the larvae presented abnormalities in the primordial marginal finfold (Pmf). These abnormalities mainly consisted of the presence of opaque, necrotic-like areas on the Pmf (Fig. 10a-a' $, \mathrm{a}^{\prime}-\mathrm{b}^{\prime}, \mathrm{d}$ ), as well as of size reduction (Fig. 10b,d), or shape alterations of the Pmf (Fig. 10c). At the metamorphosis stage, Pmf abnormalities were followed by the development of SBS at an incidence of 28-46\%.

The comparison of the skin tissue phenotype showed that normal skin is a multilayered epithelium, containing cells resembling goblet cell phenotypes (although the cell content did not stain magenta with the toluidine, as is generally the case for goblet cells) (Fig. 11). Vacuolization in the epithelial cells is limited (Fig. 11c). The specimen diagnosed with abnormalities of the primordial marginal finfold was histologically characterized by a multifocal, small epidermal erosion (epithelium completely absent) (Fig. 12c,d) with mild epithelial proliferation bordering the lesion (Fig. 12g). 


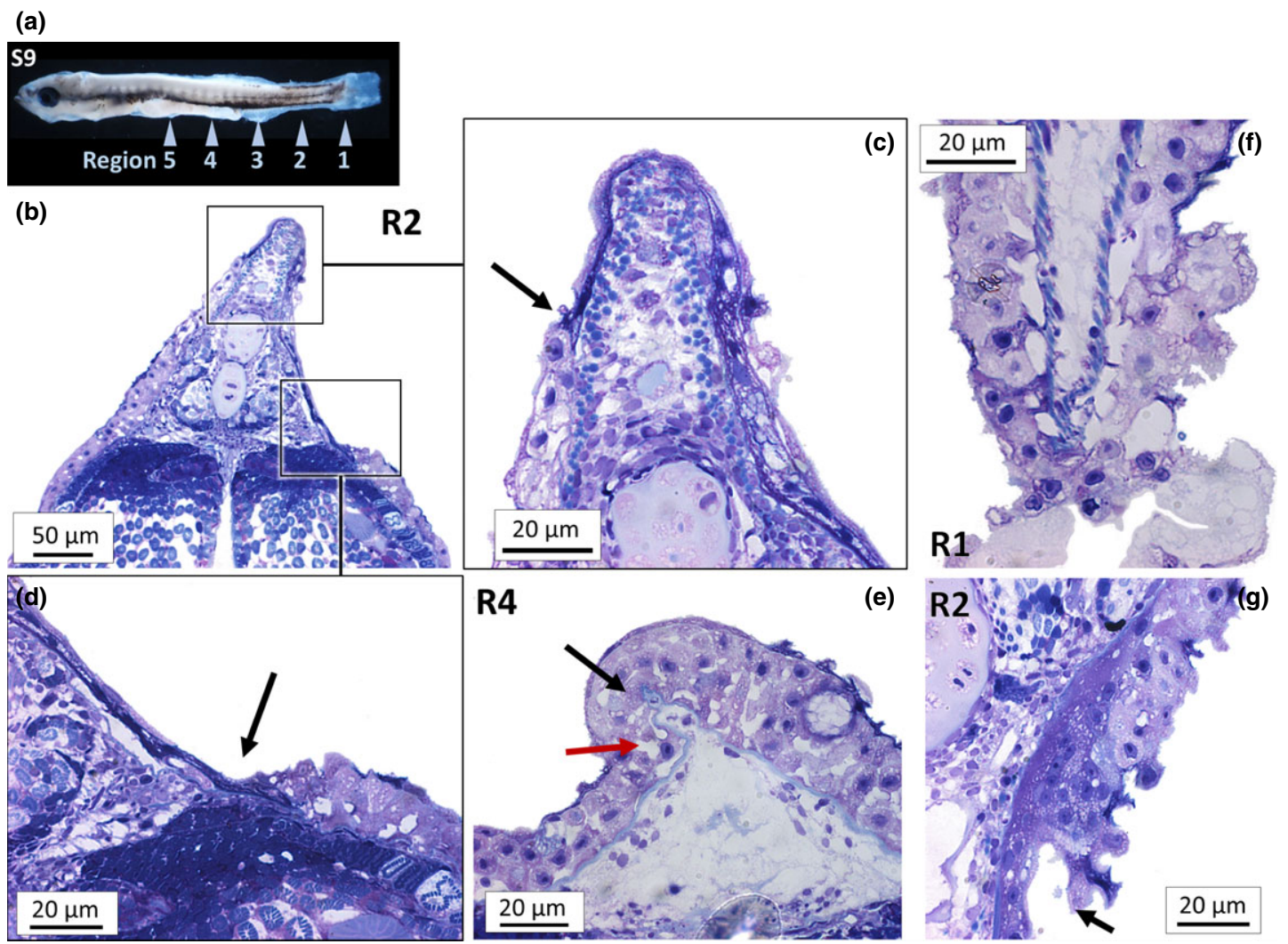

Figure 12 Skin histology in a specimen showing an abnormal primordial marginal finfold (Pmf) phenotype (specimen S9). (a) habitus of the specimen, showing the different regions from which sections were obtained. (b) overview of the dorsal fin fold in region 2. (c) inset of fig. B, showing the degenerated epidermal epithelium and hypertrophied dermal connective tissue layer (arrow shows the discrete margin from where the epidermis is missing). (d) inset of Fig. B, showing a similar degenerative border between a multilayered epidermis and a fully degenerated one. (e) detail of the dorsal skin in region 4, showing extensive intracellular (black arrow), as well as severe intercellular vacuolization oedema (red arrow). (f) detail of the ventral tail fin (region 1) showing mild and severe epidermal vacuolar degeneration and epidermal erosion. (g) detail of the lateral skin (region 2) showing epidermal proliferation, bordered by epidermal degeneration (border indicated by arrow).

In other areas, a more severe cytoplasmic vacuolization (sometimes referred to as hydropic degeneration) of epithelial cells (Fig. 12f), as well as intercellular oedema, was present (Fig. 12e).

\section{Discussion}

Saddleback syndrome has been described as an abnormality of the dorsal fin, which is externally expressed in the form of missing hard spines and in some cases lepidotrichia. Internally, SBS is characterized by severe abnormalities of the pterygiophores subjacent to the missing rays (Tave et al. 1983; Koumoundouros et al. 2001; Koumoundouros 2008; Cobcroft \& Battaglene 2013; Diggles 2013). In S. aureus, SBS has been shown to affect either the anterior, the posterior or the entire dorsal fin (Tave et al. 1983). In A. australis (Diggles 2013; Pollock 2015) and in D. dentex (Koumoundouros et al. 2001), SBS was reported to develop at the anterior and middle part of the dorsal fin. Similarly, in wild $S$. cretense SBS affected only the anterior part of the dorsal fin (Koumoundouros 2008). In the present study, SBS was shown to develop in reared D. labrax and affect either the anterior, the posterior or the entire dorsal fin. Moreover, for the first time it was shown that the lack of dorsal fin rays is not necessarily linked to abnormalities of the subjacent pterygiophores.

Previous studies demonstrate that the development of SBS is significantly correlated with the development of deformities on other fins. In S. aureus SBS was significantly correlated with 
Figure 13 Representative stages of the development of dorsal, anal and pelvic fins in sea bass (open area cartilage; stippled area ossification). (a) $7.5 \mathrm{~mm} \mathrm{SL}$. (b) $8.4 \mathrm{~mm} \mathrm{SL}$. (c) $12.0 \mathrm{~mm} \mathrm{SL}$. (d) $13.6 \mathrm{~mm} \mathrm{SL}$. (e) $18.0 \mathrm{~mm} \mathrm{SL} .\left(\mathrm{c}^{\prime}, \mathrm{d}^{\prime}, \mathrm{e}^{\prime}\right)$ ventral view of the anatomy of pelvic fins. $\left(\mathrm{e}^{\prime \prime}\right)$ magnified anatomy of the first two pterygiophores and associated fin rays of the dorsal fin. An, anus; Bp,

basipterygium; Dr, distal radial; Nc, notochord; Pmf, primordial marginal finfold; prD, predorsal; Prx, proximal pterygiophore; R, lepidotrichium (soft ray); $S$, hard spine; U, vertebral centra (only three illustrated for figure clarity); Ur, urostyle; Scale bars equal to $1 \mathrm{~mm}$ (a-e \& $\left.\mathrm{e}^{\prime \prime}\right)$ and $0.5 \mathrm{~mm}\left(\mathrm{c}^{\prime}-\mathrm{e}^{\prime}\right)$. (a)
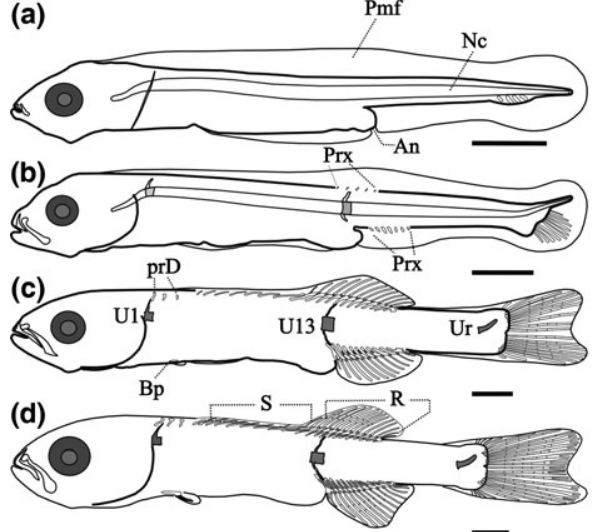

(c')

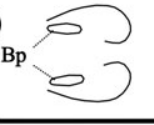

(d') s
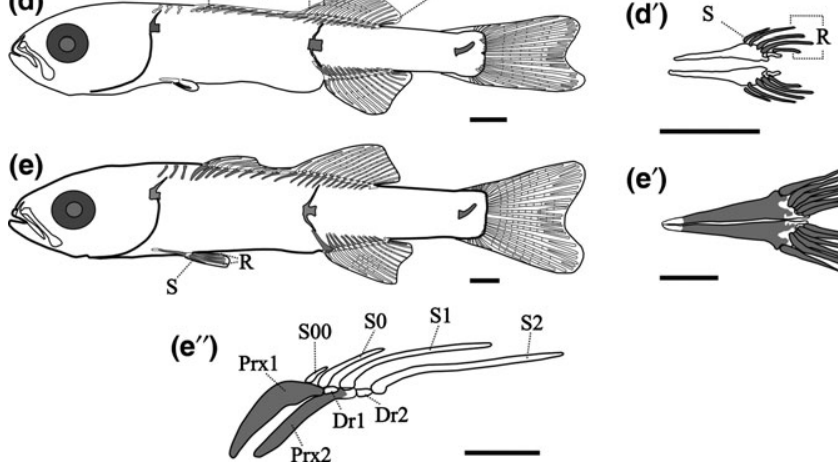

(e')

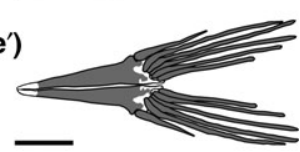

deformities of the paired fins (Tave et al. 1983), whereas in $D$. dentex and in $S$. cretense SBS was significantly correlated with deformities of the caudal fin (Koumoundouros et al. 2001; Koumoundouros 2008). In $D$. dentex, the correlation between fin deformities was attributed to early abnormalities of the primordial marginal finfold (Pmf), which appeared at both the dorsal and the caudal area (Koumoundouros et al. 2001). Similar to these previous results, the present study revealed a significant correlation of the SBS with abnormalities of the pelvic and anal fins. As in the case of D. dentex (Koumoundouros et al. 2001), in the present study, such a correlation might be attributed to the severe epidermal abnormalities which were shown to affect the dorsal and ventral part of Pmf, as well as the pelvic fin buds.

The variable expression of SBS in D. labrax, together with the correlations between different abnormality types (e.g. posterior dorsal with anal fin), could be explained under the prism of ontogeny and the hypothesis of a causative factor acting during variable ontogenetic periods. The study of the normal ontogeny of the skeleton of D. labrax clearly supports this hypothesis. The development of the posterior dorsal and the anal fin was evident at the flexion stage with the formation of some proximal pterygiophores (Prx, $8.4 \mathrm{~mm} \mathrm{SL}$; Fig. 13b). The anterior dorsal fin started developing after the attainment of full meristic count of the posterior dorsal and anal fin rays (12.0 mm SL; Fig. 13c), almost simultaneously with the appearance of the pelvic fin buds (Fig. 13c'). At the same stage, the initially uniform and transparent primordial marginal finfold was replaced by the three unpaired fins. Dorsal fin formation was completed with the development of the hard spines of the anterior dorsal fin $(13.6 \mathrm{~mm} \mathrm{SL}$; Fig. 13d), almost simultaneously with the full development of pelvic fin rays (Fig. $13 \mathrm{~d}^{\prime}$ ). In the following ontogenetic period and up to $18.0 \mathrm{~mm}$ SL, the rays of all the examined fins attained their final relative size (Fig. 13e, $\mathrm{e}^{\prime}, \mathrm{e}^{\prime \prime}$ ).

Lateral-line abnormalities were first reported in reared $S$. aurata, mainly in the form of missing sectors or zigzag patterns (Carrillo et al. 2001). In a recent study, Sfakianakis et al. (2013) reported the presence of lateral-line abnormalities in D. labrax and $S$. aurata in the form of missing sectors or double pattern. The results of the present study show that SBS may significantly be associated with abnormally missing sectors of the lateral line. Such a correlation might suggest that similar to SBS, lateral-line abnormalities are the ontogenetic result of the epidermal abnormalities developing at the flexion and metamorphosis phase. Under such a hypothesis, epidermal abnormalities might disrupt the process of epithelial ridge formation and the 
following canal segment development around each neuromast (Webb 1989). Pollock (2015) recently reported a high correlation of SBS with scale pattern deformities, with scale regeneration rate and, to a lesser extent, with lateral-line fractures in wildcaught $A$. australis. Following his results on the back-calculation of fish total length at scale loss, Pollock (2015) suggested that SBS and related scale abnormalities could be the result of physical injuries (e.g. predator-induced) in juveniles of $>70 \mathrm{~mm}$ TL. This hypothesis could not be supported by the present study, as SBS in reared D. labrax was shown to be a developmental defect appearing early in ontogeny.

A wide range of environmental stressors (e.g. heavy metals, ammonia, extreme $\mathrm{pH}$, hypoxia, drugs) and infectious agents have been reported to be associated with skin damage in fish (reviewed by Noga 2000). In the present study, skin damage was recorded at the larval phase, mainly in the form of abnormalities of the primordial marginal finfold (Pmf). In zebrafish, similar abnormalities of the Pmf are attributed to certain mutations and frequently result in abnormalities of the adult fins (Van Eeden et al. 1996). Histologically, sea bass larvae with Pmf abnormalities presented severe epidermal erosion (present study). Although the origin of epidermal abnormalities remains unclear in the present study, the fact that no significant increase in the mortality rate was observed in any of the larval populations studied (P7, P8, 40-50\% survival rate) might exclude infectious agents from the list of the potential causative factors. More research is required towards the identification of the causative factors of Pmf abnormalities, as well as for the understanding of their relationship with SBS and associated lateral-line and fin abnormalities.

\section{Acknowledgements}

This study was partially supported by the programme NSRF 2007-2013, 'Competitiveness \& Entrepreneurship' (call Cooperation I, Project No 09SYN-24-619) of the Ministry of Education, Religious Affairs, Culture and Sports, Greece. We wish to thank Barbara De Kegel (Evomorph) for making the histological sections.

\section{References}

Bardon A., Vandeputte M., Dupont-Nivet M., Chavanne H., Haffray P., Vergnet A. \& Chatain B. (2009) What is the heritable component of spinal deformities in the European sea bass (Dicentrarchus labrax)? Aquaculture 294, 194-201.

Boglino A., Darias M.J., Ortiz-Delgado J.B., Özcan F., Estévez A., Andree K.B., Hontoria F., Sarasquete C. \& Gisbert E. (2012) Commercial products for Artemia enrichment affect growth performance, digestive system maturation, ossification and incidence of skeletal deformities in Senegalese sole (Solea senegalensis) larvae. Aquaculture 324-325, 290-302.

Boglione C., Costa C., Di Dato P., Ferzini G., Scardi M. \& Cataudella S. (2003) Skeletal quality assessment of reared and wild sharpsnout sea bream and pandora juveniles. Aquaculture 227, 373-394.

Boglione C., Gisbert E., Gavaia P., Witten P.E., Moren M., Fontagné S. \& Koumoundouros G. (2013) Skeletal anomalies in reared European fish larvae and juveniles. Part 2: main typologies, occurrences and causative factors. Reviews in Aquaculture 5, S121-S167.

Browder J.A., Mcclellan D.B., Harper D.E., Kandrashoff M.G. \& Kandrashoff W. (1993) A major developmental defect observed in several Biscayne Bay, Florida, fish species. Environmental Biology of Fishes 37, 181-188.

Carrillo J., Koumoundouros G., Divanach P. \& Martinez J. (2001) Morphological malformations of the lateral line in reared gilthead sea bream (Sparus aurata L. 1758). Aquaculture 192, 281-290.

Cobcroft J.M. \& Battaglene S.C. (2009) Jaw malformation in striped trumpeter Latris lineata larvae linked to walling behaviour and tank colour. Aquaculture 289, 274282.

Cobcroft J.M. \& Battaglene S.C. (2013) Skeletal malformations in Australian marine finfish hatcheries. Aquaculture 396-399, 51-58.

Diggles B.K. (2013) Saddleback deformities in yellowfin bream, Acanthopagrus australis (Günther), from South East Queensland. Journal of Fish Diseases 36, 521-527.

Divanach P., Papandroulakis N., Anastasiadis P., Koumoundouros G. \& Kentouri M. (1997) Effect of water currents on the development of skeletal deformities in sea bass (Dicentrarchus labrax L.) with functional swimbladder during postlarval and nursery phase. Aquaculture 156, 145155 .

FEAP. (2014) European Aquaculture Production report 20052014. http://www.feap.info.

Georgakopoulou E., Katharios P., Divanach P. \& Koumoundouros G. (2010) Effect of temperature on the development of skeletal deformities in Gilthead seabream (Sparus aurata Linnaeus, 1758). Aquaculture 308, 13-19.

Gudger E.W. (1936) Beginning of fish teratology, 1555-1642. Belon, Rondelet, Gesner and Aldrovandi, the fathers of ichthyology, the first to figure abnormal fishes. The Scientific Monthly 43, 252-261.

Harder W. (1975) Anatomy of Fishes. Part I. Nägele and Obermiller, Stuttgart.

Izquierdo M.S., Socorro J. \& Roo J. (2010) Studies on the appearance of skeletal anomalies in red porgy: effect of culture intensiveness, feeding habits and nutritional quality of live preys. Journal of Applied Ichthyology 26, 320-326. 
Koumoundouros G. (2008) First record of saddleback syndrome in wild parrotfish Sparisoma cretense (L., 1758) (Perciformes, Scaridae). Journal of Fish Biology 72, 737-741.

Koumoundouros G. (2010) Morpho-Anatomical Abnormalities in Mediterranean Marine Aquaculture. Transworld Research Network, Kerala, India.

Koumoundouros G., Oran G., Divanach P., Stefanakis S. \& Kentouri M. (1997) The opercular complex deformity in intensive gilthead sea bream (Sparus aurata L.) larviculture. Moment of apparition and description. Aquaculture 156, 165-177.

Koumoundouros G., Divanach P., Savaki A. \& Kentouri M. (2000) Effects of three preservation methods on the evolution of swimbladder radiographic appearance in sea bass and sea bream juveniles. Aquaculture 182, 17-25.

Koumoundouros G., Divanach P. \& Kentouri M. (2001) The effect of rearing conditions on development of saddleback syndrome and caudal fin deformities in Dentex dentex (L.). Aquaculture 200, 285-304.

Kumar V., Abbas A.K. \& Aster J.C. (2015) Robbins \& Cotran Pathologic Basis of Disease, 9th edn. Elsevier, Philadelphia.

Loizides M., Georgiou A.N., Somarakis S., Witten P.E. \& Koumoundouros G. (2014) A new type of lordosis and vertebral body compression in Gilthead sea bream, Sparus aurata L.: aetiology, anatomy and consequences for survival. Journal of Fish Diseases 37, 949-957.

Matsuoka M. (1987) Development of the skeletal tissues and skeletal muscles in red sea bream. Bulletin of the Seikai Regional Fisheries Research Laboratory 65, 1-114.

Mazurais D., Glynatsi N., Darias M.J., Christodoulopoulou S. Cahu C.L., Zambonino-Infante J.L. \& Koumoundouros G. (2009) Optimal levels of dietary vitamin A for reduced deformity incidence during development of European sea bass larvae (Dicentrarchus labrax) depend on malformation type. Aquaculture 294, 262-270.

Negrín-Báez D., Navarro A., Lee-Montero I., Soula M., Afonso J.M. \& Zamorano M.J. (2015) Inheritance of skeletal deformities in gilthead seabream (Sparus aurata) lack of operculum, lordosis, vertebral fusion and LSK complex. Journal of Animal Science 93, 53-61.

Noga E.J. (2000) Skin ulcers in fish: Pfiesteria and other etiologies. Toxicologic Pathology 28, 807-823.

Pollock B.R. (2015) Saddleback syndrome in yellowfin bream [Acanthopagrus australis (Günther, 1859)] in Moreton Bay, Australia: its form, occurrence, association with other abnormalities and cause. Journal of Applied Ichthyology 31, 487-493.
Rohlf F.J. (2010) TpsDig, Digitize Landmarks and Outlines, Version 2.12. Department of Ecology and Evolution, State University of New York, Stony Brook, NY.

Sawayama E., Asahina K. \& Takagi M. (2014) Parentage assessment of incomplete ossification in larval Japanese flounder by microsatellite DNA markers. Aquaculture $\mathbf{4 2 0}$ 421, S98-S103.

Setiadi E., Tsumura S., Kassam D. \& Yamaoka K. (2006) Effect of saddleback syndrome and vertebral deformity on the body shape and size in hatchery-reared juvenile red spotted grouper, Epinephelus akaara (Perciformes: Serranidae): a geometric morphometric approach. Journal of Applied Ichthyology 22, 49-53.

Sfakianakis D.G., Georgakopoulou E., Papadakis I.E., Divanach P., Kentouri M. \& Koumoundouros G. (2006) Environmental determinants of haemal lordosis in European sea bass, Dicentrarchus labrax (Linnaeus, 1758). Aquaculture 254, 54-64.

Sfakianakis D.G., Katharios P., Tsirigotakis N., Doxa C.K. \& Kentouri M. (2013) Lateral line deformities in wild and farmed sea bass (Dicentrarchus labrax, L.) and sea bream (Sparus aurata, L.). Journal of Applied Ichthyology 29, 1015-1021.

Sokal R.R. \& Rohlf F.J. (1981) Biometry: The Principles and Practice of Statistics in Biological Research. W.H. Freeman, New York.

Takeuchi T., Dedi J., Haga Y., Seikai T. \& Watanabe T. (1998) Effect of vitamin A compounds on bone deformity in larval Japanese flounder (Paralichthys olivaceus). Aquaculture 169, 155-165.

Tave D., Bartels J.E. \& Smitherman R.O. (1983) Saddleback: a dominant, lethal gene in Sarotherodon aureus (Steindachner) (=Tilapia aurea). Journal of Fish Diseases 6, 59-73.

Van Eeden F.J.M., Granato M., Schach U., Brand M., Furutani-Seiki M., Haffter P., Hammerschmidt M., Heisenberg C.P., Jiang Y.J., Kane D.A., Kelsh R.N., Mullins M.C., Odenthal J., Warga R.M. \& NüssleinVolhard C. (1996) Genetic analysis of fin formation in the zebrafish, Danio rerio. Development 123, 255-262.

Walker M.B. \& Kimmel C.B. (2007) A two-color acid-free cartilage and bone stain for zebrafish larvae. Biotechnic \& Histochemistry 82, 23-28.

Webb J.F. (1989) Gross morphology and evolution of the mechanoreceptive lateral-line system in teleost fishes. Brain, Behavior and Evolution 33, 34-53.

Received: 8 February 2016

Revision received: 30 March 2016

Accepted: 30 March 2016 